BOOK REVIEW

\title{
Myths Microbes and Manipulation-Sensible Advice From the Diet Inspector: A Review of The Diet Myth by Tim Spector
}

\author{
Reviewed by Jeffrey M. Craig, Murdoch Childrens Research Institute, Royal Children's Hospital and Department of \\ Paediatrics, University of Melbourne, Melbourne, Victoria, Australia \\ doi:10.1017/thg.2016.47
}

If you want up-to-date, evidence-based dietary advice, then this is the book for you. Tim Spector is a professor at Kings College London and runs two huge studies of human health - TwinsUK and The British Gut Project. His work focuses on the genetic and environmental factors that influence our health and how we can manipulate the later to stay healthy. Each chapter covers a major food group, such as fat, protein, and carbohydrate, dispelling myths and reviewing the evidence behind current dietary advice. Spector even defines different types of evidence, from observational studies to systematic reviews.

The book is rife with fascinating tales of scientists who have taken a leap forward in their understanding of diet by self-experimenting. One of these is Spector himself, who leads the reader through his odyssey to find the perfect diet and the effects of various diets on the diversity of bacteria within his gut.

The book is very easy to read for a general audience, and no previous knowledge of science or medicine is required. A spoonful of humor and tasty titbits of trivia now and again make the text even more palatable. But perhaps the most ingratiating side of the book is the message that science and scientists are fallible. We sometimes misinterpret our results. We may try to pursue our favorite theory but ultimately a good scientist will admit they were wrong when presented with credible evidence to the contrary.

The main narrative running throughout this book is the microbiota - the myriad bugs that live on and in you and whose cell numbers are at least equal to yours. We share our bodies with beneficial and harmful bugs, an excess of the former ideally keeping the latter in check. Bugs dine on the food we eat, and in turn, they produce some extremely useful byproducts such as vitamins, and even molecules such as neurotransmitters that signal to the brain and alter our behavior. For the past 50 or so years, a revolution has being going on in our guts. The number of bacterial species each of us carry around has been shrinking. We have been feeding them too much processed food, too much meat, and a dwindling variety of fruit and vegetables. Feeding them too little of the starches that we can't digest but they can. The big incentive of dieting is that in so-called developed countries like Australia, the United Kingdom and the United States, approximately two thirds of the adult population are overweight or obese and this number is growing. Obesity confers an elevated risk of diabetes, heart disease, and stroke. Poor diet is also likely to be a major contributor to many cancers and many mental health conditions.

As expected, twin research features heavily in this book. Spector makes reference to twin studies in areas as diverse as chocolate consumption, exercise, food preferences, lactose intolerance, vegetarianism, weight gain, bone strength, and of course, microbiota. In particular, working with a large number of twin participants, Spector himself has shown that although non-shared environment is the biggest component of variance to microbiota diversity, a small group of bacterial phyla and genera are highly heritable. In addition, an illustration of the power of the discordant $\mathrm{MZ}$ co-twin model is given, in which such studies found a much smaller effect on BMI of a vegan diet compared to an omnivorous diet. Spector stresses that twin studies are essential to 
control for genetic and shared environmental effects, especially when the results of such studies inform health policy.

What diet does Spector recommend from all the available evidence from dietary and nutritional research? We now know that most fats are good for us in moderation, with extra virgin olive oil, raw or cooked, being one of the healthiest. We know that nuts, grain coffee and dark chocolate are all good for us, again in moderation. We know that variety is king and that every fruit and vegetable is a 'superfood' because of all the good chemicals they contain, from vitamins to starches and polyphenols. On the other hand, vitamin and omega three supplements are generally useless to most of us; some vitamin supplements, such as calcium, can also be harmful when taken in excess. Artificial sweeteners don't fare too well too in this book either. We now know that the amount of added sugar in our diets, especially fructose (from the corn syrup much loved by junk food manufacturers), is bad for us. It gets sent straight to our livers where it gets turned into fat. It also poisons our good bugs. We know that indiscriminate use of broad spectrum antibiotics in our livestock and in us is destroying many of our beneficial bugs.

Elective C-sections are also criticized because only when babies come out the 'natural' way do they get coated in mum's beneficial bacteria, which lessens their risk of chronic disease. With unavoidable C-sections, some parents are beginning to take things into their own hands, as it were, and rub a swab from mum's vagina all over babies born this way; although some have urged caution over this practice due the possibility of transferring harmful bacteria. Spector also urges us not to be too clean; to allow our kids to roll around in the dirt, own pets, engage in 'heavy petting' with farm animals, to hold back on products such as household cleaners and mouthwash that wipe out the good with the bad bacteria. He also rues the chances we are missing by not having access to properly regulated raw milk and cheese. However, he suggests we all eat more good bug-containing probiotics such as kimchi, sauerkraut, live (full-fat) yoghurt, and pickles. He also recommends an occasional fast - for example that in the 5:2 diet, which involves general restriction of food intake two days per week.

Finally, Spector urges us to think not of specific ingredients but of the big picture: our dietary patterns. He also urges us to consider ourselves and our microorganisms unique. We all react to foods in a slightly different way, and in the future, our health can only be optimized by first knowing more about our microbes and our own genetics. The future is in our hands. And in our guts. 